\title{
The role of subglacial hydrology in ice streams with elevated geothermal heat flux
}

\section{Paper}

Cite this article: Smith-Johnsen S, de Fleurian B, Nisancioglu KH (2020). The role of subglacial hydrology in ice streams with elevated geothermal heat flux. Journal of Glaciology 66(256), 303-312. https://doi.org/ $10.1017 /$ jog.2020.8

Received: 22 August 2019

Revised: 10 January 2020

Accepted: 13 January 2020

First published online: 10 February 2020

\section{Keywords:}

Glacier hydrology; ice dynamics; ice-sheet modelling; ice streams; melt-basal

\section{Author for correspondence:}

Silje Smith-Johnsen, E-mail: Silje.Johnsen@ uib.no

(c) The Author(s) 2020. This is an Open Access article, distributed under the terms of the Creative Commons Attribution licence (http:// creativecommons.org/licenses/by/4.0/), which permits unrestricted re-use, distribution, and reproduction in any medium, provided the original work is properly cited.
Silje Smith-Johnsen ${ }^{1}\left(\mathbb{D}\right.$, Basile de Fleurian ${ }^{1}(\mathbb{D})$ and Kerim H. Nisancioglu ${ }^{1,2}$ (D)

${ }^{1}$ Department of Earth Science, University of Bergen, Bjerknes Centre for Climate Research, Norway and ${ }^{2}$ Centre for Earth Evolution and Dynamics, University of Oslo, Norway

\section{Abstract}

The spatial distribution of geothermal heat flux (GHF) under ice sheets is largely unknown. Nonetheless, it is an important boundary condition in ice-sheet models, and suggested to control part of the complex surface velocity patterns observed in some regions. Here we investigate the effect of including subglacial hydrology when modelling ice streams with elevated GHF. We use an idealised ice stream geometry and a thermomechanical ice flow model coupled to subglacial hydrology in the Ice Sheet System Model (ISSM). Our results show that the dynamic response of the ice stream to elevated GHF is greatly enhanced when including the interactive subglacial hydrology. On the other hand, the impact of GHF on ice temperature is reduced when subglacial hydrology is included. In conclusion, the sensitivity of ice stream dynamics to GHF is likely to be underestimated in studies neglecting subglacial hydrology.

\section{Introduction}

Geothermal heat flux (GHF) impacts the basal thermal regime of ice sheets (Rogozhina and others, 2012; Seroussi and others, 2017). Whether the bed reaches the pressure melting point or not determines whether surface velocities are controlled by sliding at the base or internal deformation. GHF has two main effects on ice dynamics: it affects internal flow through its impact on ice temperature altering the ice rheology (Glen, 1955) and it can increase the sliding rates by providing basal meltwater in regions otherwise not subject to surface water input. Basal meltwater lubricates the bed and thus facilitates sliding. For this reason, high GHF anomalies are thought to initiate and sustain some ice streams (Blankenship and others, 1993; Bourgeois and others, 2000; Fahnestock and others, 2001; Näslund and others, 2005; Bell, 2008; Winsborrow and others, 2010; Rogozhina and others, 2016). GHF is one of the least known boundary conditions in ice-sheet models, and uncertainties in GHF may explain why surface velocities in some regions are not well reproduced in models without inverting for basal conditions.

Estimates of GHF under the Greenland Ice Sheet have been derived from direct measurements at a few deep ice core drilling sites (e.g. GRIP Members, 1993; NGRIP Members, 2004; NEEM Community Members, 2013). Studies using tectonic (Pollack and others, 1993), seismic (Shapiro and Ritzwoller, 2004) and magnetic (Fox Maule and others, 2009) models to retrieve spatial maps of GHF show little agreement, indicating large uncertainties in both its magnitude and spatial distribution (Rogozhina and others, 2012). Bore hole measurements have been used to refine GHF maps through the use of ice-sheet models (Tarasov and Peltier, 2003; Greve, 2005; Pattyn, 2010; Greve, 2019).

In addition to containing large uncertainties, GHF maps are coarse and do not capture potential elevated heat flux anomalies shown to exist (Carson and others, 2014; Schroeder and others, 2014; Fisher and others, 2015). Rogozhina and others (2016) produced a GHF map for the Greenland Ice Sheet indicating a large heat flux anomaly in the north east, supporting the proposed idea that the Northeast Greenland Ice Stream (NEGIS) may be initiated by these elevated heat fluxes (Fahnestock and others, 2001; Rezvanbehbahani and others, 2017; Rysgaard and others, 2018).

Motivated by large uncertainties in GHF, previous modelling studies have been carried out to investigate the impact of GHF on the ice sheets thermal regime (e.g. Rogozhina and others, 2012; Seroussi and others, 2017). Most studies agree that GHF plays an important role in determining the temperature at the bed, and hence where the bed reaches pressure melting point and how much ice melts in these regions (Greve and Hutter, 1995; Brinkerhoff and others, 2011; Seroussi and others, 2017). Rogozhina and others (2012) did a thorough analysis of the differences between existing GHF maps for the Greenland Ice Sheet and assessed their implication for the thermal regime as well as the ice geometry. They concluded that for paleoclimatic simulations (last $150 \mathrm{ka}$ ) the GHF has a major impact on ice topography, in agreement with Greve and Hutter (1995). Pollard and others (2005) on the other hand investigated the sensitivity of the Cenozoic Antarctic Ice Sheet to GHF, and found that reasonable variations in GHF had very little impact on the simulated ice volume and ice extent.

Previous modelling studies have also focused on the impact of GHF on ice dynamics and particularly ice streams (Näslund and others, 2005; Larour and others, 2012a; Robel and others, 2013; Schlegel and others, 2015; Pittard and others, 2016a). Large uncertainties in GHF have little influence on ice dynamics on short time scales (Larour and others, 2012b; 
Schlegel and others, 2015), but significant impact on longer timescales in paleoclimatic simulations (Näslund and others, 2005).

As stated by Pollard and others (2005); the most important way GHF impacts ice dynamics is through its effect on water pressure at the bed and the subsequent modifications in basal sliding, and thus this hydrological effect has been included in GHF studies (Robel and others, 2013; Pittard and others, 2016a). Robel and others (2013) found that GHF controls two modes of ice streaming behaviour in their model: they calculate till strength, which is dependent on water content, and sliding occurs when the driving stress exceeds the till strength threshold. With a simple hydrology model, Pittard and others (2016a) investigated the role of elevated GHF on ice flow in the Lambert-Amery region (Antarctica). In their study, GHF was producing meltwater and filling up a till layer that induces sliding when saturated. They concluded that slow flowing areas are highly sensitive to an increase in GHF, but that this was not the case for fast flowing areas.

Pollard and others (2005) stress that GHF impacts sliding in models by increasing basal temperature to the pressure melting point, which initiates sliding. This mechanism referred to as the 'all-or-nothing' switch does not account for an increase in basal melt caused by higher GHF in regions where the ice is already at the pressure melting point. Effective pressure, defined as the difference between the ice overburden pressure and water pressure (Cuffey and Paterson, 2010), has a major impact on observed ice velocity variations (Schoof, 2005). Hence, it is important to include effective pressure in the friction law in order to capture increasing basal melting rates caused by the enhanced GHF. None of the previous GHF sensitivity studies include effective pressure and its impact on ice dynamics. Understanding the links between GHF, effective pressure and sliding may provide useful insight to better reproduce the observed complex flow patterns observed in high GHF regions, such as the NEGIS.

In this study we investigate the role of subglacial hydrology in regions with elevated GHF. We particularly focus on the influence of including effective pressure in the friction law and analyse positive and negative feedbacks arising in the model. We first describe the model used and outline the model set-up including boundary conditions and experimental design. Then we present our findings from the different experiments with varying configurations of subglacial hydrology. Next, we discuss the impact of a GHF anomaly, the limitations of the model, and compare our findings to previous result. Finally, we conclude on the impact of subglacial hydrology in ice streams with elevated GHF.

\section{Methods}

\section{Model description}

We use the Ice Sheet System Model (ISSM), a thermomechanical finite-element ice flow model conserving mass, momentum and energy. This state-of-the-art model contains a range of capabilities presented in Larour and others (2012b). Here we describe briefly the relevant components for this study.

In ISSM ice is treated as a purely viscous incompressible material (Cuffey and Paterson, 2010), with viscosity, $\mu$, following Glen's flow law (Glen, 1955):

$$
\mu=\frac{B}{2 \dot{\epsilon}_{\mathrm{e}}^{(n-1) / n}}
$$

where $B$ is the temperature dependent ice hardness varying with depth, $n$ is Glen's flow law exponent and $\dot{\epsilon}_{\mathrm{e}}$ is the effective strain rate. For calculating the stress balance we apply the hybrid L1L2 scheme (Hindmarsh, 2004) as an approximation to the Stokes equations. For the computation of the ice temperature, basal melt rates and the conservation of energy we use the thermal model described in Larour and others (2012b) including conduction-advection in three dimensions. We apply a standard friction law calculating basal drag after Cuffey and Paterson (2010):

$$
\boldsymbol{\tau}_{\mathrm{b}}=-\alpha^{2} N^{r}\left|\mathbf{v}_{\mathrm{b}}\right|^{s-1} \mathbf{v}_{\mathrm{b}}
$$

where $\tau_{\mathrm{b}}$ is basal stress, $\alpha$ is a friction coefficient, $\mathbf{v}_{\mathrm{b}}$ basal velocity and $N$ is effective pressure. $r$ and $s$ are defined as

$$
r=q / p, \quad s=1 / p,
$$

where $p$ and $q$ are friction law exponents.

We use a two-layered subglacial hydrology model from de Fleurian and others (2016) including both inefficient and efficient drainage systems represented as porous layers with different conductivities. The inefficient drainage system is always active, but the efficient drainage system may activate or collapse through time. Activation occurs as the local effective pressure reaches zero. The thickness of the efficient layer evolves similarly to the size of subglacial channels (Röthlisberger, 1972), and it deactivates when reaching a defined collapse threshold. We exclude surface water input in order to focus on the basal conditions, and the only source of water is given by the basal melt. The source for the efficient layer is a transfer term between the two layers; a flux driven by water head differences between the two drainage systems. The water pressure of the inefficient drainage system is used to compute the effective pressure. For more details about the subglacial hydrology model, see de Fleurian and others (2014) and de Fleurian and others (2016).

Here we have, for the first time, coupled the subglacial hydrology model to the thermomechanical ice flow model in ISSM. The ice flow model provides basal melting rates and geometry for the subglacial hydrology model, which computes effective pressure. Effective pressure is coupled to the ice flow model through the friction law (Eqn (2)), thus impacting both the stress balance and the thermal component of the ice flow model. We set the effective pressure equal to overburden pressure where the bed is frozen, and update this as basal temperatures evolve.

\section{Experiment set-up}

\section{Geometry}

For geometry and parameter selection we use the idealised ice stream model set-up modified from the Marine Ice Sheet Model Intercomparison Project (MISMIP+ Asay-Davis and others, 2016). Parameters outside the MISMIP+ description were guided by observations from NEGIS in addition to the Subglacial Hydrology Model Intercomparison Project (de Fleurian and others, 2018). The domain is $640 \mathrm{~km}$ long in the $x$ direction and $80 \mathrm{~km}$ wide in the $y$ direction (Fig. 1). The model uses an anisotropic mesh with spatial resolution of $2.5 \mathrm{~km}$, extruded vertically to 15 layers. A summary of the parameters used in the study is given in Table 1 .

\section{Boundary conditions}

At the glacier surface, temperature is prescribed as a Dirichlet boundary condition. We set temperatures to $-10^{\circ} \mathrm{C}$ at sea level with a lapse rate of $-0.007^{\circ} \mathrm{C} \mathrm{m}^{-1}$ based on mean annual air temperatures (2013-2015) from the PROMICE weather stations in the vicinity of NEGIS (KPCL and KPCU, www.promice.org). As the surface elevation of the ice stream changes, so does the surface temperature following the lapse rate. Surface mass balance is applied uniformly with a value of $\dot{M}_{\mathrm{s}}=0.3 \mathrm{~m} \mathrm{a}^{-1}$, following MISMIP+ (Asay-Davis and others, 2016). At the base of the ice 

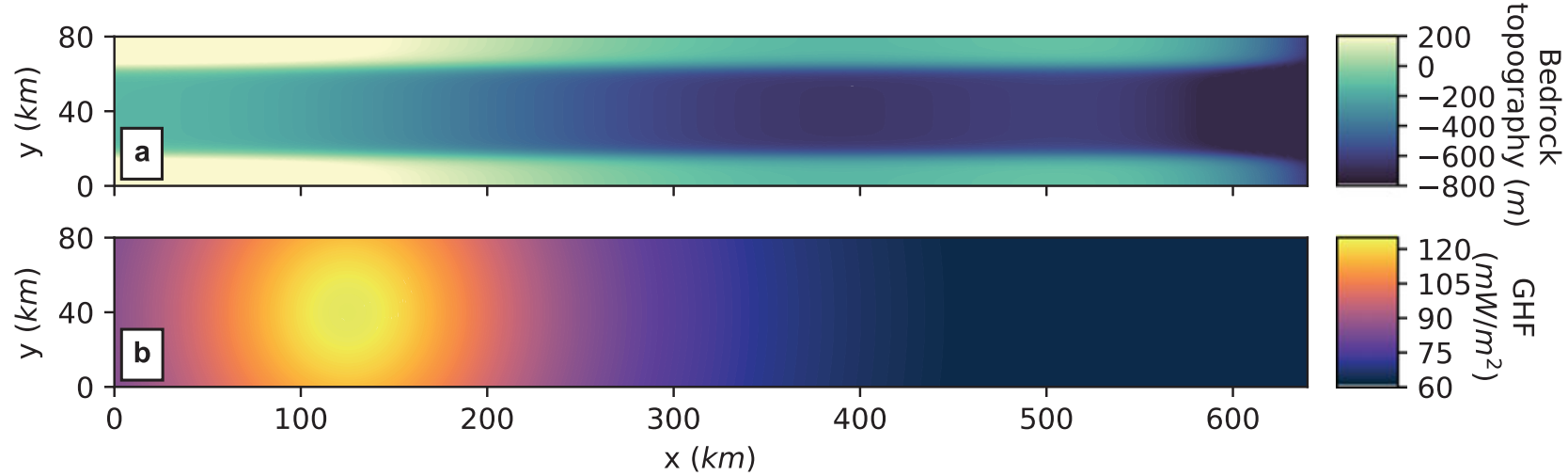

Fig. 1. Model domain for the experiments where $x$-values show distance from the ice divide, $y$-values show width of the idealised ice stream. Figure a shows bedrock elevation of the ice stream trough. Figure b shows the computed geothermal heat flux (GHF) values used in the experiment.

Table 1. Definitions and reference values of variables, parameters and constants in the model

\begin{tabular}{|c|c|c|c|}
\hline Symbol & Description & Unit & Value \\
\hline$\alpha$ & Basal friction coefficient & $\left(m s^{-1}\right)^{-1 / 2}$ & 75 \\
\hline$B$ & Glen's flow law parameter & $\mathrm{Pa}^{-n} \mathrm{~s}^{-1}$ & \\
\hline$\dot{\epsilon}_{\mathrm{e}}$ & Effective strain rate & $s^{-1}$ & \\
\hline$G$ & Geothermal heat flux & $\mathrm{mW} \mathrm{m} \mathrm{m}^{-2}$ & 63 \\
\hline$g$ & Gravitational acceleration & $\mathrm{m} \mathrm{s}^{-2}$ & 9.81 \\
\hline$H$ & Ice thickness & $\mathrm{m}$ & \\
\hline$L$ & Latent heat of fusion & $\mathrm{J} \mathrm{kg}^{-1}$ & $3.35 \times 10^{5}$ \\
\hline$\dot{M}_{\mathrm{b}}$ & Basal melt rate & $\mathrm{m} \mathrm{a}^{-1}$ & \\
\hline$\dot{M}_{\mathrm{s}}$ & Surface accumulation & $\mathrm{m} \mathrm{a}^{-1}$ & 0.3 \\
\hline$\mu$ & Ice viscosity & Pa s & \\
\hline$N$ & Effective pressure & $\mathrm{Pa}$ & \\
\hline$n$ & Glen's flow law exponent & & 3 \\
\hline$p$ & Friction law exponent & & 1 \\
\hline$\rho_{\mathrm{i}}$ & Ice density & $\mathrm{kg} \mathrm{m}^{-3}$ & 917.0 \\
\hline$\rho_{w}$ & Water density & $\mathrm{kg} \mathrm{m}^{-3}$ & 1000.0 \\
\hline$q$ & Friction law exponent & & 1 \\
\hline$\tau_{\mathrm{b}}$ & Basal shear stress & $\mathrm{Pa}$ & \\
\hline$T_{\mathrm{j}}$ & IDS transmissivity & $\mathrm{m}^{2} \mathrm{~s}^{-1}$ & 0.02 \\
\hline$T_{\mathrm{m}}$ & Melting point of ice & $\mathrm{K}$ & 273.15 \\
\hline $\mathbf{v}_{\mathrm{b}}$ & Basal velocity & $\mathrm{m} \mathrm{a}^{-1}$ & \\
\hline $\bar{v}$ & Depth-average velocity & $\mathrm{m} \mathrm{a}^{-1}$ & \\
\hline
\end{tabular}

the following Neumann boundary condition is applied in the thermal model:

$$
k_{\mathrm{th}} \nabla T \cdot \mathbf{n}=G-\boldsymbol{\tau}_{\mathrm{b}} \cdot \mathbf{v}_{\mathrm{b}}
$$

The left side of the equation is the heat flux applied at the glacier bed, where $k_{\text {th }}$ is ice thermal conductivity, $\nabla T$ the temperature gradient and $\mathbf{n}$ the normal vector to the ice-bed interface. The right side is the GHF, $G$, and the frictional heat computed as the product of the basal velocity, $\mathbf{v}_{\mathrm{b}}$, and basal drag, $\tau_{\mathrm{b}}$. GHF is temporally constant and uniformly distributed with a value of $G=63 \mathrm{~mW} \mathrm{~m}^{-2}$, representing the average for the Greenland Ice Sheet (Rogozhina and others, 2012). The basal temperature is constrained to not exceed the melting point, and the excess heat is used to formulate the basal melt rate, $\dot{M}_{\mathrm{b}}$ :

$$
\dot{M}_{\mathrm{b}}=\frac{k_{\mathrm{th}}}{\rho_{\mathrm{i}} L}\left(\frac{\partial T^{*}}{\partial z}-\frac{\partial T}{\partial z}\right)
$$

where $L$ is the latent heat of fusion, $\rho_{i}$ the ice density, $T^{*}$ is the temperature computed before applying the constraints and $T$ is the temperature after.

Boundary conditions for the stress balance model are as follows: at the ice divide there is a no-slip boundary condition, free-slip boundaries at the lateral margins $(y=0$ and $80 \mathrm{~km})$, and stress-free boundary conditions at the surface. No calving law is applied, instead ice is removed beyond $x=640 \mathrm{~km}$ as in the MISMIP + setup.

We use the default friction law in ISSM, with $p=q=1$ in Eqn (3), reducing it to:

$$
\boldsymbol{\tau}_{\mathrm{b}}=-\alpha^{2} N \mathbf{v}_{\mathrm{b}}
$$

The friction coefficient $\alpha$ is spatially uniform and the value is based on a preceding study by Schlegel and others (2015). From this study we computed our $\alpha$ as the mean value of their friction coefficient taken outside of the main trunk of NEGIS (velocities below $40 \mathrm{~m} \mathrm{a}^{-1}$ ). Values for the parameters in the hydrology model were chosen to reach an overall mean floatation fraction of 0.7 , similar to used for Russel glacier by de Fleurian and others (2016), resulting in a $1 \mathrm{~m}$ thick sediment layer with transmissivity of $T_{\mathrm{j}}=0.02 \mathrm{~m}^{2} \mathrm{~s}^{-1}$. Other parameters in the hydrology set-up follow the one from the $b f$ models in SHMIP (de Fleurian and others, 2018). The time step in the ice flow model is 1 year and for the hydrology model we use 1 day, both satisfying the Courant-Friedrichs-Lewy condition.

\section{Experiments}

The model was initialised and spun up for $100 \mathrm{ka}$ to obtain a steady state with ice volume change less than $0.001 \% \mathrm{a}^{-1}$ (Fig. 2). For the spin-up the masstransport, stress balance and the thermal solution were computed for all time steps, and the effective pressure computed every $5 \mathrm{ka}$. Temperature, velocity and thickness for the the initial state are shown in Figure 3. From this initial state we branch into two thermal steady-state simulations, with different GHF configurations (Fig. 2). In the first case we keep the same GHF configurations as the initial state (uniform $G=63 \mathrm{~mW} \mathrm{~m}^{-2}$ ) and this becomes our Ctrl simulation. In the second case we force the model with a GHF anomaly computed by a mantle plume module in ISSM equal to Plume A in Seroussi and others (2017). The resulting GHF configuration is shown in Figure $1 \mathrm{~b}$, and has a maximum magnitude of $128 \mathrm{~mW} \mathrm{~m}^{-2}$, decreasing to similar values as the Ctrl simulation within $200 \mathrm{~km}$. The GHF anomaly has a higher value than that suggested for North East Greenland by Grinsted and Dahl-Jensen (2002), Rogozhina and others (2016), Rysgaard and others (2018) and Dahl-Jensen and others (2003), but similar to what Greve (2019) suggested for NGRIP, and much weaker than suggested by Fahnestock and others (2001) and Alley and others (2019) $\left(970 \mathrm{~mW} \mathrm{~m}^{-2}\right)$.

From the thermal steady state with the GHF anomaly we branch into three experiments (Fig. 2), which differ in their 


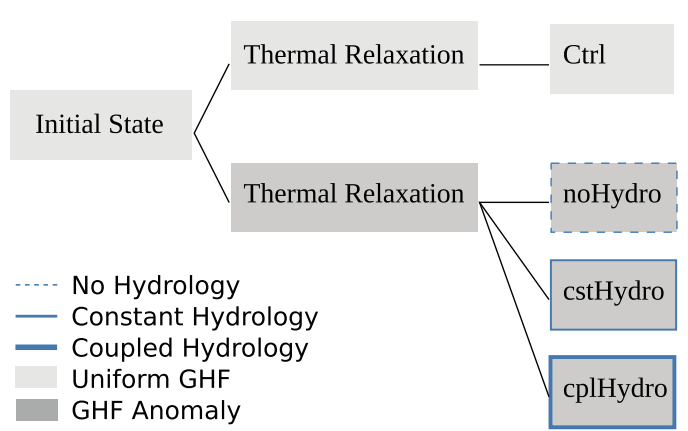

Fig. 2. Model flow chart for the control and three experiments. The leftmost box illustrates the initial state, which is the end of the $100 \mathrm{ka}$ spin-up. The middle column represents the thermal relaxation step where the upper model is forced with a uniform geothermal heat flux like the initial state, and the lower model is forced with a geothermal heat flux anomaly, both in thermal steady state. The last column represents the control and the three different experiments. The control keeps both the GHF and the effective pressure from the initial state. The three experiments are forced with a GHF anomaly and differ by their degree of hydrological interaction with ice dynamics.

degree of the hydrological interaction with ice dynamics in the model simulation. In the first experiment (noHydro) we use the same effective pressure as in the Ctrl simulation, and change the thermal state. For the second experiment (cstHydro), we compute the effective pressure for the new thermal state and keep this field constant in time. In the third experiment (cplHydro) the subglacial hydrology model is offline coupled to the ice flow model. We use a loose coupling where a new hydrological steady state is recomputed every 500 years, to comply with the temporal evolution of both ice geometry and basal melt rates.

We use this gradual build up of complexity in our three experiments to disentangle the feedbacks and isolate the role of hydrology when investigating the influence of enhanced GHF on ice dynamics. In noHydro we study the effect GHF has on ice rheology alone. For cstHydro we introduce the hydrological effect and investigate the influence of GHF on sliding. Finally, in
cplHydro we look into how the GHF influences the dynamics of the ice stream as hydrology and geometry interact, and positive and negative feedbacks arise.

As a sudden appearance of a GHF anomaly is not what we aim to investigate, but rather the influence of a permanent anomaly, we run all the experiments and the $\mathrm{Ctrl}$ simulation for $5 \mathrm{ka}$ to reach equilibrium, and consider only the final time step. For cplHydro, it is challenging to reach true steady state, as this requires tight and computationally heavy coupling of the thermomechanical ice flow and the subglacial hydrology, which is not yet feasible in ISSM. Instead, we run the experiment until water pressure and ice thickness only show minor adjustments between two consecutive coupling steps.

\section{Results}

The impact of the elevated GHF, on both the dynamics and the thermal regime of the ice stream, differs between the three hydrology configurations. We first describe the Ctrl simulation, before presenting the response of the ice stream to the GHF anomaly in each of the experiments; noHydro, cstHydro and cplHydro.

\section{Control (Ctrl)}

In Figure 3 we present a map view of the key variables for the Ctrl simulation after $5 \mathrm{ka}$, for the upstream part of the domain. Note that we only show the upper $350 \mathrm{~km}$ of the domain, as we focus on how the GHF anomaly may influence the onset of the ice stream. Figure $3 \mathrm{a}$ shows the melt rates for the basal layer, with no melt at the ice divide and values increasing as we go downstream. Regions where the bed remains below pressure melting point are indicated with a transparent mask. This shows that a substantial part of the upper $150 \mathrm{~km}$ of the ice stream is cold based, in addition to a region downstream at the side of the trough. The corresponding effective pressure (Fig. 3b) confirms
Fig. 3. Map view of key variables of the $\mathrm{Ctrl}$ simulation after $5 \mathrm{ka}$, ice flows to the right. Figure a shows basal melt rates, figure $b$ effective pressure, figure $c$ surface velocity and figure $d$ ice thickness $(H)$. Transparent masks indicate where the bed is below the pressure melting point. Note that we only show the upper $350 \mathrm{~km}$ part of the domain.
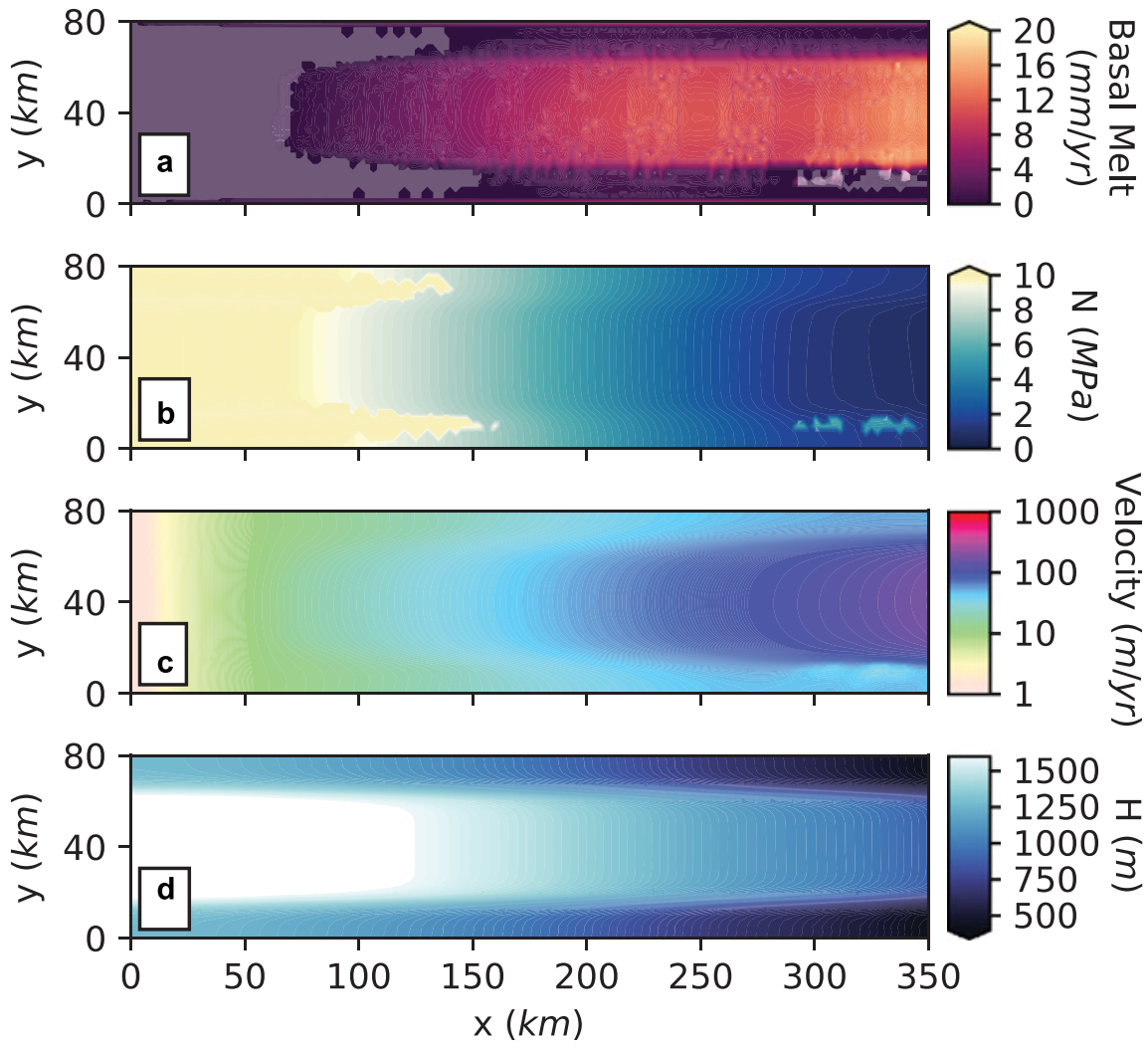

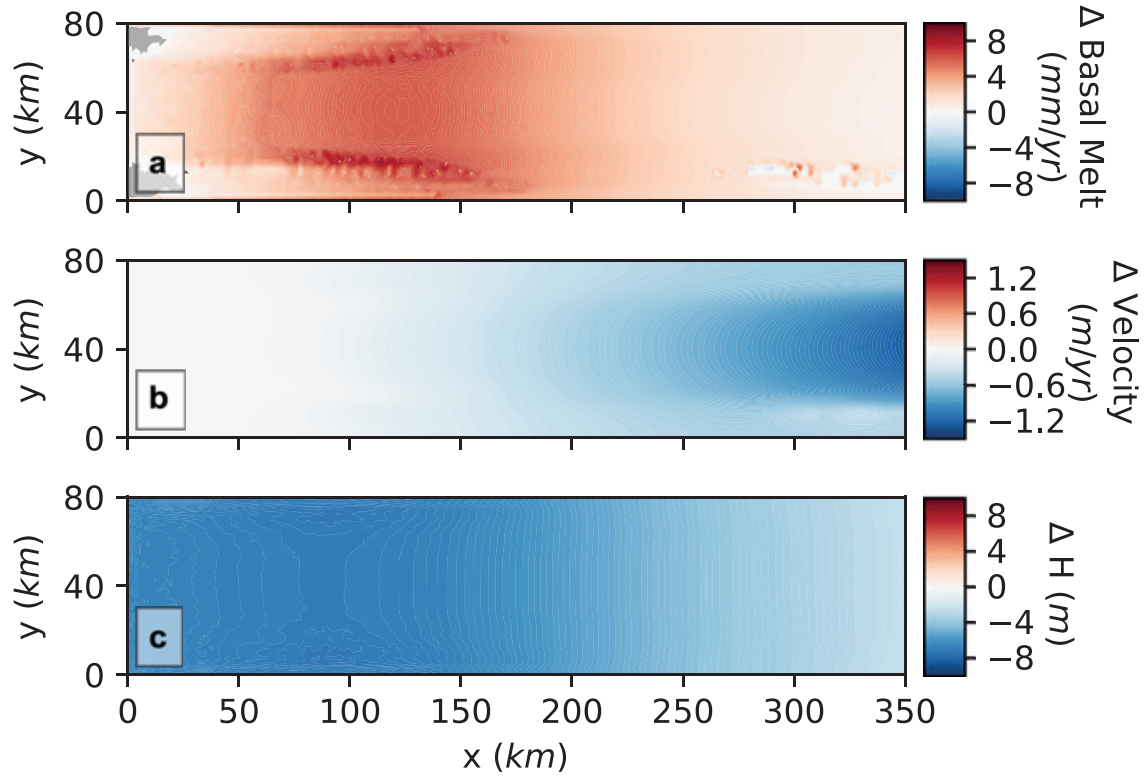

Fig. 4. Map view of the spatial impact of the GHF anomaly for the simulation without subglacial hydrology. Shown are the differences of the results (noHydro - Ctrl) at the end of the simulations for (a) basal melt rates, (b) surface velocity and (c) ice thickness. Grey region indicates where the bed is below pressure melting point.

that the upper part of the domain is frozen, and thus displays effective pressure values equal to the overburden ice pressure. The effective pressure is decreasing downstream and reaches zero at the grounding line. The pattern in effective pressure results in slow velocity (Fig. 3c) at the ice divide and the fastest velocities at the grounding line. The ice stream is thickest at the centre of the trough with highest values at the ice divide and reaching the minimum thickness at the margins towards the grounding line (Fig. 3d). The ice stream is grounded at $x=400 \mathrm{~km}, 50 \mathrm{~km}$ further upstream than the original MISMIP+ experiments (Asay-Davis and others, 2016). The geometry of the Ctrl run is plotted along the centre of the trough in Figure 7 (grey).

\section{No hydrology (noHydro)}

The introduction of an elevated GHF anomaly in the system without subglacial hydrology influences the basal thermal regime, but has a negligible dynamic impact. In Figure 4 we present the spatial differences between the noHydro and Ctrl simulations after $5 \mathrm{ka}$. We observe an increase in basal temperatures as the GHF anomaly is introduced, resulting in higher basal melt rates (Fig. 4a). The surface velocity above the GHF anomaly towards the ice divide remains unchanged (Fig. 4b). However, we observe a slow-down of the ice stream downstream towards the grounding line. The changes in velocity are relatively small, with a maximum of $1.3 \mathrm{~m} \mathrm{a}^{-1}$ change in a region with surface velocity of $200 \mathrm{~m} \mathrm{a}^{-1}$. The spatial pattern of the thickness variations show an overall lowering of the ice surface (Fig. 4c), with the largest changes directly above the GHF anomaly and reduced thinning downstream. The surface profile along the centre of the trough is shown in Figure 7 (light grey), and it falls on top of the Ctrl surface geometry, indicating minimal changes.

\section{Constant hydrology (cstHydro)}

The influence of the elevated heat flux anomaly is more complex in the experiment with constant hydrology. In Figure 5 we present the spatial differences between cstHydro and Ctrl after $5 \mathrm{ka}$. We observe an increase in temperature in the GHF anomaly region, inducing higher basal melt rates (Fig. 5a). The increase in basal melt above the anomaly is $5.1 \mathrm{~mm} \mathrm{a}^{-1}$, compared to $6.2 \mathrm{~mm} \mathrm{a}^{-1}$ in $n o H y d r o$ (Fig. 4a). However, the ice stream displays a decrease in basal melt rates $100 \mathrm{~km}$ downstream of the GHF anomaly. Higher temperatures thaw the upstream part of the domain towards the ice divide, which is frozen in the Ctrl simulation, leaving only the margins of the ice divide still frozen (grey corners in Fig. 5b). The modifications in the basal melt field lead to major changes in the distribution of effective pressure (Fig. 5b), with a lowering of effective pressure all over the domain apart from the ice divide. The decrease is particularly apparent in the region that is frozen in $\mathrm{Ctrl}$, and thawed in the cstHydro. The lowering of effective pressure leads to a speed-up of the ice stream (Fig. 5c), with a higher than $50 \mathrm{~m} \mathrm{a}^{-1}$ increase in velocity, representing a 50\% speed-up. The ice stream displays an asymmetric velocity pattern at the grounding line, caused by the frozen region at the margin (Fig. $3 b$, grey area). However, we observe a slow-down of the margins on each side of the maximum speed-up, inducing a more focused velocity pattern. The overall increased velocity causes a thinning of up to $400 \mathrm{~m}$ of the ice stream (Fig. 5d). The surface profile along the centre of the trough is given in Figure 7 (light blue), showing a flattening of the surface $100 \mathrm{~km}$ upstream of the grounding line, caused by the dynamic thinning.

\section{Coupled hydrology (cplHydro)}

The same GHF anomaly introduced in the coupled ice dynamicsubglacial hydrology system gives a less pronounced dynamic effect, relative to cstHydro. The impact of the GHF anomaly is presented spatially in Figure 6 as the difference between cplHydro and Ctrl after $5 \mathrm{ka}$. The increase of the GHF leads to an increase in basal melt rates of the same magnitude as in cst Hydro, but extending further downstream (Fig. 6a). We observe a similar drop in effective pressure as in cstHydro (Fig. 6b), but a larger area of the domain remains frozen, stretching $50 \mathrm{~km}$ downstream from the ice divide at each margin (Fig. 6, grey area). As the effective pressure is lowered, the entire ice stream speeds up (Fig. 6c). However, the speed-up is lower in magnitude (average $24 \mathrm{~m} \mathrm{a}^{-1}$ ) relative to the cstHydro simulation (average $42 \mathrm{~m} \mathrm{a}^{-1}$ ), and we do not observe a slow-down of the margins. The resulting ice stream thickness shows a thinning compared to the Ctrl simulation, of up to $400 \mathrm{~m}$ (Fig. 6d). Relative to the cstHydro simulation, the thinning is of similar magnitude at the ice divide, but less widespread and diminishes towards the grounding line. The surface geometry along the centre of the trough is shown in Figure 7 (blue), and shows an overall flattening of the surface, caused by the thinning. The resulting surface is thus thicker and less steep compared to cstHydro (light blue). 
Fig. 5. Map view of the spatial impact of the GHF anomaly for the simulation with constant hydrology. Shown are the differences of the results with and without a geothermal heat anomaly (cstHydro Ctrl) for (a) basal melt rates, (b) effective pressure, (c) surface velocity and (d) ice thickness. Grey region indicates where the bed is below pressure melting point.
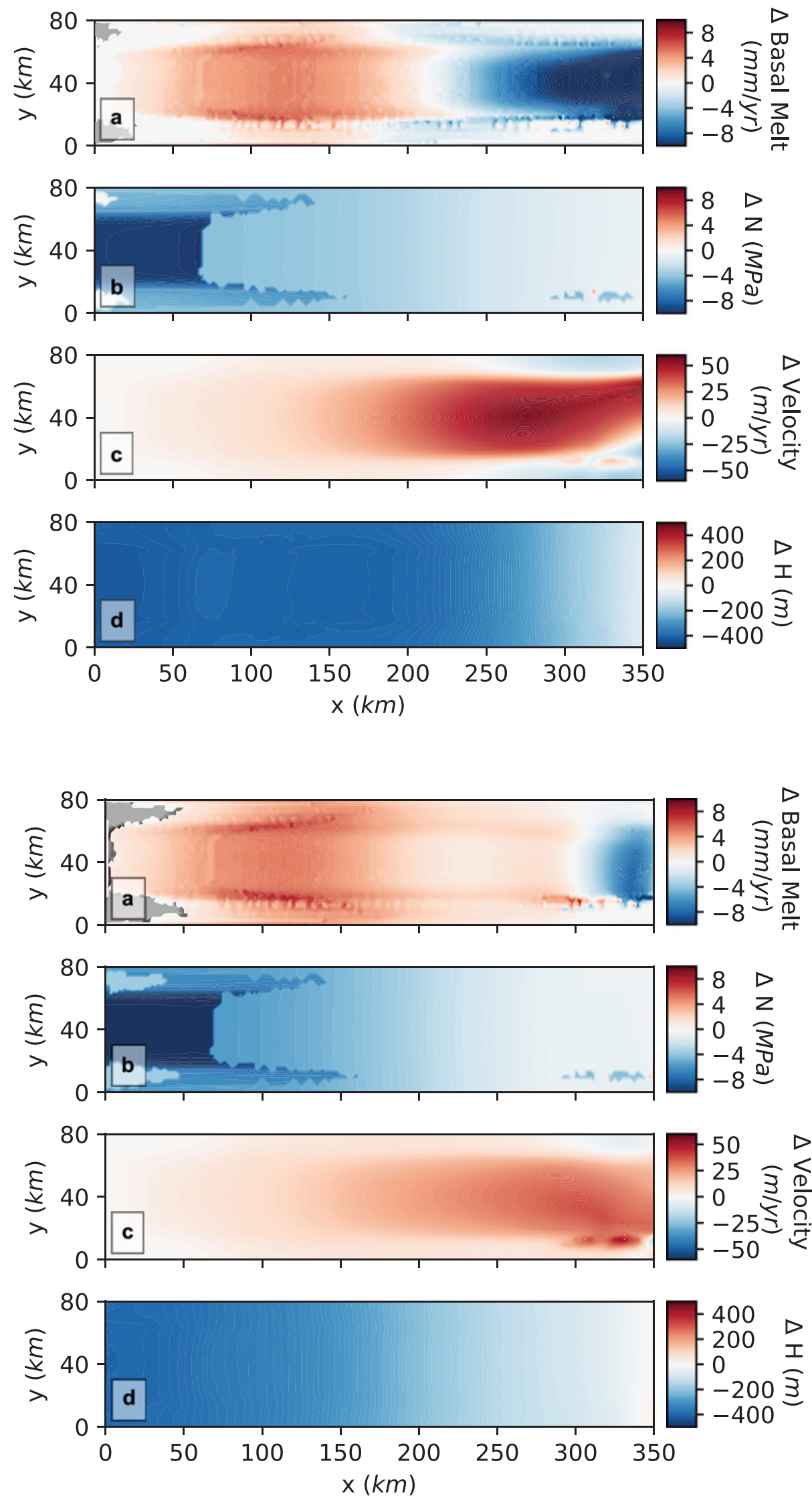

Fig. 6. Map view of the spatial impact of the GHF anomaly for the simulation with coupled hydrology. Shown are the differences of the results with and without a geothermal heat anomaly (cplHydro - Ctrl) for (a) basal melt rates, (b) effective pressure, (c) surface velocity and (d) ice thickness. Grey region indicates where the bed is below pressure melting point.

\section{Discussion}

Here we investigate the effect of including subglacial hydrology in the model and assess the influence of a local high in GHF on the dynamics and thermal regime of an ice stream. We find that geometric and dynamic changes in response to a local enhancement of GHF are significantly larger in the experiments with hydrology relative to without hydrology. When comparing the experiments including hydrology, the dynamic response to the 


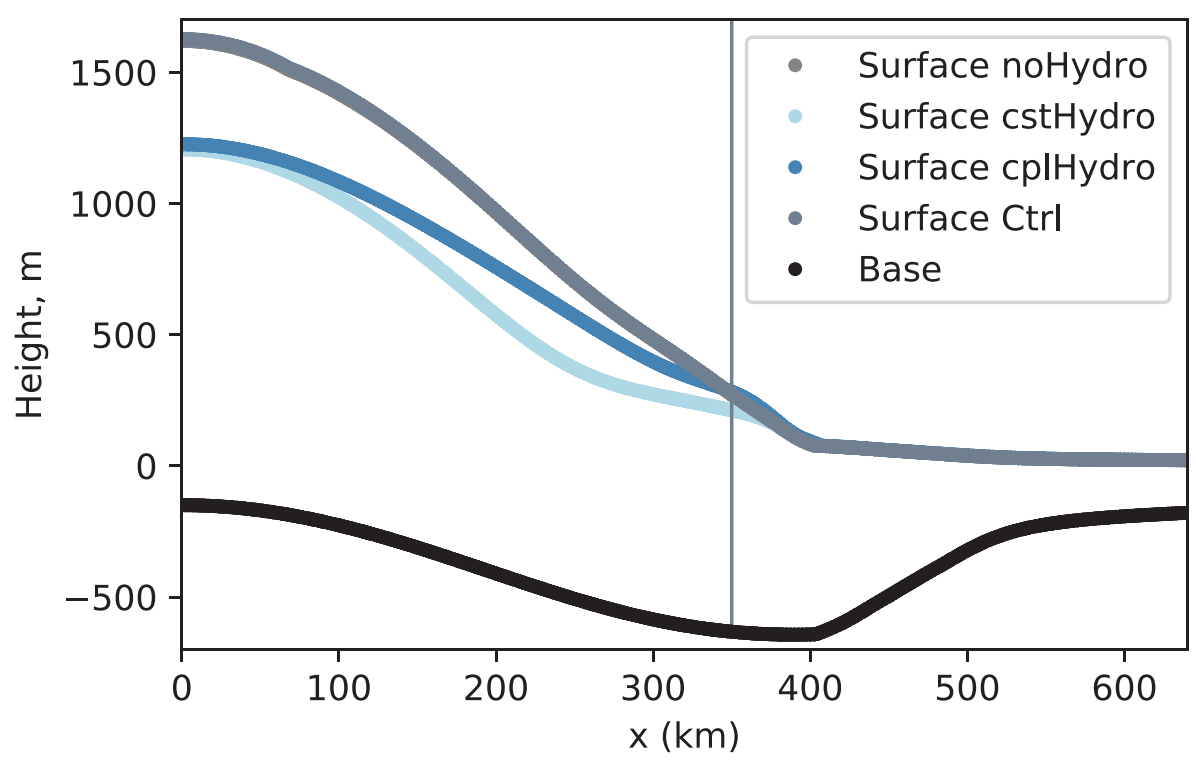

Fig. 7. Surface profiles at the end of the experiments, plotted along the centreline of the ice stream. Surface of Ctrl is shown in grey, cstHydro in light blue and cplHydro in blue. The black line shows the base, with grounding line at $x \approx 400 \mathrm{~km}$. Note, surface for noHydro falls on top of Ctrl. The vertical grey line indicates the position of the downstream boundary of Figures 3-6.
GFH anomaly is more pronounced in the simulation with temporally constant hydrology (cstHydro) than in the simulation with interactive hydrology (cplHydro).

In the simulation without subglacial hydrology (noHydro), the dynamic influence of the GHF anomaly is small, as expected. On the other hand, the decrease in velocity downstream of the anomaly (Fig. 4b) is not expected. We explain this by higher basal melt rates in noHydro relative to Ctrl (Fig. 4a), leading to a thinning of the ice stream (Fig. 4c). The thinning induces a surface slope flattening, decreasing the driving stress (not shown), ultimately causing a slow-down of the ice stream (Fig. 4b). Counter-intuitively, instead of the elevated heat flux warming and softening the ice and enhancing the flow, the elevated heat flux causes a thinning and deceleration of the ice stream. This slow down occurs because the bed is already close to, or at, the pressure melting point before the GHF anomaly is introduced (Fig. 3a). We expect the results to be different if the extra heat applied, instead of mostly melting basal ice, increases the temperature of the ice column. Similar negative feedbacks with cold ice advection was recognised by Oerlemans (1983) and Van Pelt and Oerlemans (2012) prohibiting further speed-up in their simulations.

Larour and others (2012a) investigated the impact of propagating GHF errors on ice hardness, and how this influenced mass flux in Pine Island Glacier. They concluded that, in fast flowing regions, a change of up to $50 \mathrm{~mW} \mathrm{~m}^{-2}$ in GHF only leads to a $1 \%$ change in the mass flux. Schlegel and others (2015) did a similar study of the Northeast Greenland Ice Stream, and for the region with velocities closest to our simulations, uncertainty in GHF resulted in a minor change in mass flux. Pollard and others (2005) also concluded that a reasonable change in GHF had very little impact on ice dynamics. Similarly, the noHydro experiment shows a minor dynamic response to a doubling in GHF, and thus our findings agree with previous studies.

The inclusion of an elevated GHF anomaly in the constant hydro simulation (cstHydro) resulted in a substantial thinning and acceleration of the glacier. Velocity increases as a response to higher melt rates and drives the water pressure up, causing a reduction in effective pressure, and therefore lower basal drag (Fig. 5). The acceleration displays an asymmetric pattern towards the grounding line, which we explain by the downstream frozen area (Fig. 3, transparent mask). The asymmetric basal temperatures is caused by the anisotropic model mesh, leading to an asymmetric development of the efficient drainage system. Where the efficient drainage system activates, water pressure is reduced and velocity decreases, inducing less frictional heat. This causes one of the margins of the ice stream to freeze, and where basal melt rates are zero, the effective pressure is prescribed equal to the overburden ice pressure, thus leading to higher basal drag on one side of the ice stream. We acknowledge that this may be a numerical artefact as a result of the mesh resolution, this may change with a change in mesh resolution. For a prediction, or quantification study, using a realistic ice stream geometry, it is recommended to further refine the model mesh in fast flowing areas where the melt is high due to frictional heat. However, since this is a study of a synthetic ice stream with a focus on the upstream dynamic response to geothermal heat we find the model resolution sufficient.

Counter-intuitively, the ice stream cools in a region with accelerating ice flow, where one might expect warming due to an increase in frictional heat. The overall thinning may explain the observed cooling and reduced basal melt rates downstream of the GHF anomaly (Fig. 5a), as a result of less insulation and a change in the pressure melting point. Increased velocities also cause a draw-down of colder surface ice, cooling the ice column. The area around the GHF anomaly naturally does not cool, as this is compensated by the enhanced GHF. In the cstHydro simulation the surface temperature is fixed, despite changes in the surface height (in the cplHydro it is updated every 500 years). This influences the amount of heat advected and diffused towards the base. The observed cooling is thus overestimated, and the downstream cooling observed would be less pronounced if the surface temperature were to respond to changes in altitude.

The coupled hydrology simulation (cplHydro) displays an extensive dynamic response to the enhanced GHF: there is a significant thinning upstream, and the ice stream accelerates from the ice divide to the grounding line (Figs 6b,c). However, as hydrology is coupled to ice dynamics, and responds to changes in geometry (thinning), the resulting equilibrium state is thicker and flatter for cplHydro relative to cstHydro. As a consequence of the higher insulating effect of the thicker ice stream, cplHydro exhibits more extensive basal melt (Fig. 7). The downstream part of cplHydro cools similar to cstHydro, in an area where the GHF is minimally enhanced (Fig. 1). The less steep surface geometry of the ice stream in cplHydro, compared to cstHydro, results in smaller driving stress and reduced flow. Another reason why the cstHydro is showing a more pronounced speed-up than the cplHydro is the more extensive efficient drainage system in cplHydro (not shown). As a consequence, the water 
from the GHF anomaly is more efficiently evacuated away, resulting in higher effective pressure and thus a lesser increase in ice velocity in cplHydro.

The impact on velocity by the GHF anomaly in the runs including hydrology (cstHydro and cplHydro) is larger than observed by previous studies such as Larour and others (2012a) and Schlegel and others (2015) involving ice streams with similar velocities. These studies do not include a hydrology model, and thus do not capture the influence from a change in basal drag. More importantly, their small sensitivities to GHF are largely due to ice velocities being highly sensitive to friction coefficients, which are inverted from observed surface velocities. Hence, most errors due to GHF are compensated by carrying out this inversion. These previous investigations showing small sensitivities of the mass flux in glaciers to GHF can be explained by neglecting subglacial hydrology. On the other hand, Pittard and others (2016a) used a simple hydrology model to capture the effect of regions with elevated heat flux and we expect their simulations to be similar to cstHydro. However, Pittard and others (2016a) do not observe a significant influence from the GHF anomaly in areas with similar velocity as our experiments. Despite a strong GHF anomaly ( $\sim 3$ times the background value), no melting occurs, thus the response they observe is mostly due to changes in the ice softness, similar to our noHydro experiment.

We observe a smaller thermal imprint of the GHF anomaly in the simulations with hydrology, compared to noHydro (Figs 4 and 6). Negative feedbacks arising with hydrological coupling have been recognised previously by Hoffman and Price (2014), investigating the impact of a moulin in various hydrological configurations with increasing complexity. Similar decreases in temperature and thinning were observed by Gudlaugsson and others (2017) when investigating the sensitivity of the Eurasian ice sheet to hydrology. They concluded that models without subglacial hydrology coupled to ice dynamics overestimated the area of temperate ice due to the exclusion of the negative feedback arising when water enhanced sliding advected cold ice downstream. Brinkerhoff and others (2011) found a diminishing sensitivity of the frozen/thawed boundary to increasingly higher GHF, and also concluded it to be due to the inability to overcome cold advected ice from upstream.

The subglacial hydrology drainage system of fast flowing ice is difficult, or even impossible to observe, thus leaving the hydrology model parameter space highly uncertain and unconstrained. The conductivity of the drainage system impacts the efficiency in evacuating water and therefore controls the sensitivity of the system to water input. With a lower conductivity, the dynamic response to the GHF anomaly will be enhanced, as the same water input will in this case result in a higher water pressure and hence reduced friction. A change in both the sediment thickness and transmissivity would therefore impact our results. We expect the hydrology system close to the ice divide of an ice stream to be inefficient with low conductivity, therefore the model may underestimate the dynamic response of the ice stream to the GHF anomaly.

In this study we use a simple friction law where basal drag depends linearly on the effective pressure. The friction law is a crucial link between the subglacial hydrology and the ice dynamics, and a different choice of friction law would likely change our results. Particularly, the friction law used in the MISMIP+ experiments (Asay-Davis and others, 2016; Tsai and others, 2015) includes effective pressure only where the coulomb criterion is met, usually near the grounding line. This friction law would hence give a less dynamic response to the upstream changes in effective pressure from the GHF anomaly observed in our experiments. Therefore, by using a simple friction law we may overestimate the sensitivity of the ice stream to GHF anomalies. Unfortunately, defining a universal friction law remains one of the biggest challenges in glaciology.

In the cplHydro experiment, we use a coupling with a relatively long coupling time of 500 years, where the hydrology model is run to steady state for every coupling step. After $5 \mathrm{ka}$, we reach two consecutive coupling steps in which neither water head, nor the ice geometry changes significantly. We still observe minor oscillations in ice geometry between the coupling steps, however the changes are small relative to the preceding coupling steps and the differences between the three experiments. We therefore find this loose coupling approach sufficient to serve the purpose of this paper. Coupling thermomechanical ice flow models to sophisticated subglacial hydrology models is in its infancy, and future studies should focus on how to fully couple these models and investigate how coupling time influences ice dynamics and oscillations.

Including subglacial hydrology models computing the effective pressure in ice flow models will have implications for future GHF studies in regions where the bed is at the pressure melting point. Our results imply that previous studies may have underestimated the sensitivity of ice flow to elevated heat flux, and overestimated the influence on basal melt rates, by excluding subglacial hydrology. The negative feedbacks arising by the inclusion of subglacial hydrology may be of particular interest for studies like Greve (2019), using ice flow models to constrain GHF values by matching modelled basal temperatures to observed ones. As GHF maps become less uncertain and more detailed, and in order to capture the impact of this, effective pressure must be included in the friction laws of ice flow models. This is particularly important for studies predicting future ice-sheet behaviour where one cannot invert for basal drag, as surface velocity observations do not exist and basal drag is thought to change with a changing climate.

Including effective pressure in friction laws will help resolve the complex flow patterns observed in the Greenland Ice Sheet (Beyer and others, 2018). The increase in velocity in both our cstHydro and cplHydro experiments agree with the hypothesis that NEGIS and other ice streams may be initiated by elevated GHF anomalies (Fahnestock and others, 2001; Rogozhina and others, 2016; Alley and others, 2019). At present, ice-sheet models are not able to reproduce the characteristic upstream flow pattern of NEGIS (Goelzer and others, 2018). Including a local GHF anomaly and a subglacial hydrology model is the key to solve this in future studies.

\section{Conclusions}

We have investigated the impact of using a subglacial hydrology model on the dynamic and thermal response of an ice stream to elevated geothermal heat flux. Our results indicate that ice streams are more sensitive to GHF than previously shown in studies excluding the impact on effective pressure. With a locally enhanced GHF, we find increased velocities and substantial thinning of the ice stream, and the effect is significantly larger in experiments including subglacial hydrology. We observe an insignificant dynamic impact of GHF in the experiment without hydrology, despite the melt rates being higher. This suggest that previous studies excluding hydrology may have underestimated the dynamic and overestimated the thermal effects. On long timescales, the coupled ice dynamics-hydrology system shows a dampened response to the elevated GHF anomaly, due to the negative feedbacks hindering the expected warming and speed-up. Including subglacial hydrology in models may help to reproduce the observed complex velocity pattern in ice sheets, particularly the NEGIS, suggested to be induced by highGHF. 
Contribution statement. The study was designed and developed by the three authors. SSJ performed the simulations and wrote the paper with contributions from BdF and $\mathrm{KHN}$.

Acknowledgments. SSJ, BdF and KHN have received funding from the European Research Council under the European Community's Seventh Framework Programme (FP7/2007-2013) ERC grant agreement 610055 as part of the ice2ice project. BdF received funding from Bjerknes Centre strategic project RISES. The computations were performed on resources provided by UNINETT Sigma2 - the National Infrastructure for High Performance Computing and Data Storage in Norway (nn4659k and nn9635k). We thank Nicole Schlegel for inspiration and help with ISSM and Helene Seroussi for providing her MISMIP+ set-up in ISSM and for support with ISSM. Finally, we thank Andy Aschwanden and one anonymous reviewer for greatly improving the manuscript.

\section{References}

Alley RB and 8 others (2019) Possible role for tectonics in the evolving stability of the Greenland ice sheet. Journal of Geophysical Research 124(1), 97-115. doi: 10.1029/2018JF004714

Asay-Davis XS and 13 others (2016) Experimental design for three interrelated marine ice sheet and ocean model intercomparison projects: MISMIP v. 3 (MISMIP +), ISOMIP v. 2 (ISOMIP +) and MISOMIP v. 1 (MISOMIP1). Geoscientific Model Development 9(7), 2471-2497. doi: 10. 5194/gmd-9-2471-2016

Bell RE (2008) The role of subglacial water in ice-sheet mass balance. Nature Geoscience 1(5), 297-304. doi: 10.1038/ngeo186

Beyer S, Kleiner T, Aizinger V and Humbert A (2018) A confined-unconfined aquifer model for subglacial hydrology and its application to the North East Greenland Ice Stream. The Cryosphere 12, 39313947. doi: 10.5194/tc-2017-221)

Blankenship DD and 5 others (1993) Active volcanism beneath the West Antarctic ice sheet and implications for ice-sheet stability. Nature 361 (6412), 526-529. doi: 10.1038/361526a0

Bourgeois O, Dauteuil O and van Vliet-Lanoe B (2000) Geothermal control on flow patterns in the last glacial maximum ice sheet of Iceland. Earth Surface Processes and Landforms 25, 59-76. doi: 10.1002/(SICI)1096-9837 (200001) 25

Brinkerhoff DJ, Meierbachtol TW, Johnson JV and Harper JT (2011) Sensitivity of the frozen/melted basal boundary to perturbations of basal traction and geothermal heat flux: Isunnguata Sermia, western Greenland. Annals of Glaciology 52(59), 43-50. doi: 10.3189/172756411799096330

Carson CJ, McLaren S, Roberts JL, Boger SD and Blankenship DD (2014) Hot rocks in a cold place: high sub-glacial heat flow in East Antarctica. Journal of the Geological Society 171(1), 9-12. doi: 10.1144/jgs2013-030

Cuffey KM and Paterson WSB (2010) The Physics of Glaciers. Academic Press.

Dahl-Jensen D, Gundestrup N, Gogineni SP and Miller H (2003) Basal melt at NorthGRIP modeled from borehole, ice-core and radio-echo sounder observations. Annals of Glaciology 37, 207-212. doi: 10.3189/ 172756403781815492

de Fleurian B and 6 others (2014) A double continuum hydrological model for glacier applications. Cryosphere 8(1), 137-153. doi: 10.5194/ tc-8-137-2014

de Fleurian B and 8 others (2016) A modeling study of the effect of runoff variability on the effective pressure beneath Russell Glacier, West Greenland. Journal of Geophysical Research 121(10), 1834-1848. doi: 10. 1002/2016JF003842

de Fleurian B and 11 others (2018) SHMIP the subglacial hydrology model intercomparison project. Journal of Glaciology 64(248), 897-916. doi: 10 1017/jog. 2018.78

Fahnestock M, Abdalati W, Joughin I, Brozena J and Gogineni P (2001) High geothermal heat flow, basal melt, and the origin of rapid ice flow in Central Greenland. Science 294(5550), 2338-2342. doi: 10.1126/science. 1065370

Fisher AT, Mankoff KD, Tulaczyk SM and Tyler SW (2015) High geothermal heat flux measured below the West Antarctic ice sheet. Science Advances 1(July), 1-9. doi: 10.1126/sciadv.1500093

Fox Maule C, Purucker ME and Olsen N (2009) Inferring magnetic crustal thickness and geothermal heat flux from crustal magnetic field models,
Estimating the geothermal heat flux beneath the Greenland ice sheet. Danish Climate Centre Report, 9(09)

Glen JW (1955) The creep of polycrystalline ice. Proceedings of the Royal Society of London. Series A. Mathematical and Physical Sciences 228 (1175), 519-538. doi: 10.1098/rspa.1955.0066

Goelzer H and 28 others (2018) Design and results of the ice sheet model initialisation initMIP-Greenland: an ISMIP6 intercomparison. Cryosphere 12 (4), 1433-1460. doi: 10.5194/tc-12-1433-2018

Greenland Ice-core Project (GRIP) Members (1993) Climate instability during the last interglacial period recorded in the GRIP ice core. Nature 364 (6434), 203-207. doi: 10.1038/364203a0

Greve R (2005) Relation of measured basal temperatures and the spatial distribution of the geothermal heat ux for the Greenland ice sheet. Annals of Glaciology 42, 424-432. doi: 10.3189/172756405781812510

Greve R (2019) Geothermal heat flux distribution for the Greenland ice sheet, derived by combining a global representation and information from deep ice cores. Polar Data Journal 3, 22-36. doi: 10.20575/00000006

Greve R and Hutter K (1995) Polythertnal three-dimensional modelling of the Greenland ice sheet with varied geothermal heat flux. Annals of Glaciology 21, 8-12. doi: 10.3189/S0260305500015524

Grinsted A and Dahl-Jensen D (2002) A Monte Carlo-tuned model of the flow in the NorthGRIP area. Annals of Glaciology 35, 527-530. doi: 10. $3189 / 172756402781817130$

Gudlaugsson E and 5 others (2017) Eurasian ice-sheet dynamics and sensitivity to subglacial hydrology. Journal of Glaciology 63(239), 556-564. doi: 10. 1017/jog.2017.21

Hindmarsh R (2004) A numerical comparison of approximations to the Stokes equations used in ice sheet and glacier modeling. Journal of Geophysical Research: Earth Surface 109(May), 1-15. doi: 10.1029/ 2003JF000065

Hoffman M and Price S (2014) Feedbacks between coupled subglacial hydrology and glacier dynamics. Journal of Geophysical Research 119(3), 414-436. doi: 10.1002/2013JF002943

Larour E, Morlighem M, Seroussi H, Schiermeier J and Rignot E (2012a) Ice flow sensitivity to geothermal heat flux of Pine Island Glacier, Antarctica. Journal of Geophysical Research 117(4), 1-12. doi: 10.1029/2012JF002371

Larour E, Seroussi H, Morlighem M and Rignot E (2012b) Continental scale, high order, high spatial resolution, ice sheet modeling using the Ice Sheet System Model (ISSM). Journal of Geophysical Research 117(January), F01022. doi: 10.1029/2011JF002140

Näslund JO, Jansson P, Fastook JL, Johnson J and Andersson L (2005) Detailed spatially distributed geothermal heat-flow data for modeling of basal temperatures and meltwater production beneath the Fennoscandian ice sheet. Annals of Glaciology 40, 95-101. doi: 10.3189/172756405781813582

NEEM Community Members (2013) Eemian interglacial reconstructed from a Greenland folded ice core. Nature 493(7433), 489-494. doi: 10.1038/ nature11789

North Greenland Ice Core Project (NGRIP) Members (2004) High-resolution record of Northern Hemisphere climate extending into the last interglacial period. Nature 431(September), 147-151. doi: 10.1038/nature02805

Oerlemans J (1983) A numerical study on cyclic behaviour of polar ice sheets. Tellus 35A, 81-87. doi: 10.3402/tellusa.v35i2.11421

Pattyn F (2010) Antarctic subglacial conditions inferred from a hybrid ice sheet/ice stream model. Earth and Planetary Science Letters 295(3-4), 451-461. doi: 10.1016/j.epsl.2010.04.025

Pittard ML, Galton-Fenzi BK, Roberts JL and Watson CS (2016) Organization of ice flow by localized regions of elevated geothermal heat flux. Geophysical Research Letters. doi: 10.1002/2016GL068436

Pollack HN, Hurter SJ and Johnson JR (1993) Heat flow from the Earth's interior: analysis of the global data set. Reviews of Geophysics 31(3), 267280. doi: 10.1029/93RG01249

Pollard D, DeConto RM and Nyblade AA (2005) Sensitivity of Cenozoic Antarctic ice sheet variations to geothermal heat flux. Global and Planetary Change 49(1-2), 63-74. doi: 10.1016/j.gloplacha.2005.05.003

Rezvanbehbahani S, Stearns L, Kadivar A, Walker D and van der Veen CJ (2017) Predicting the geothermal heat flux in Greenland: A machine learning approach. Geophysical Research Letters. doi: 10.1002/2017GL075661

Robel AA, Degiuli E, Schoof C and Tziperman E (2013) Dynamics of ice stream temporal variability: modes, scales, and hysteresis. Journal of Geophysical Research 118(2), 925-936. doi: 10.1002/jgrf.20072

Rogozhina I and 6 others (2012) Effects of uncertainties in the geothermal heat flux distribution on the Greenland ice sheet: an assessment of existing 
heat flow models. Journal of Geophysical Research 117(F2), 1-16. doi: 10.1029/2011JF002098

Rogozhina I and 9 others (2016) Melting at the base of the Greenland ice sheet explained by Iceland hotspot history. Nature Geoscience 9(April), 66-69. doi: 10.1038/ngeo2689

Röthlisberger H (1972) Water pressure in intra- and subglacial channels. Journal of Glaciology 11(62), 177-203. doi: 10.1017/ S0022143000022188

Rysgaard S, Bendtsen J, Mortensen J and Sejr MK (2018) High geothermal heat flux in close proximity to the Northeast Greenland ice stream. Scientific Reports 8(1), 1-8. doi: 10.1038/s41598-018-19244-x

Schlegel NJ, Larour E, Seroussi H, Morlighem M and Box JE (2015) Ice discharge uncertainties in Northeast Greenland from climate forcing and boundary conditions of an ice flow model. Journal of Geophysical Research 120, 29-54. doi: 10.1002/2014JF003359

Schoof C (2005) The effect of cavitation on glacier sliding. Proceedings of the Royal Society A: Mathematical, Physical and Engineering Sciences 461 (2055), 609-627. doi: 10.1098/rspa.2004.1350

Schroeder DM, Blankenship DD, Young DA and Quartini E (2014) Evidence for elevated and spatially variable geothermal flux beneath the West Antarctic ice sheet. Proceedings of the National Academy of Sciences of the United States of America 111(25), 9070-9072. doi: 10.1073/pnas. 140518411

Seroussi H, Ivins ER, Wiens DA and Bondzio J (2017) Influence of a West Antarctic mantle plume on ice sheet basal conditions. Journal of Geophysical Research 122(9), 7127-7155. doi: 10.1002/2017JB014423

Shapiro NM and Ritzwoller MH (2004) Inferring surface heat flux distributions guided by a global seismic model: particular application to Antarctica. Earth and Planetary Science Letters 223(1-2), 213-224. doi: 10.1016/j.epsl. 2004.04.011

Tarasov L and Peltier WR (2003) Greenland glacial history, borehole constraints, and Eemian extent. Journal of Geophysical Research 108(B3), 1-20. doi: $10.1029 / 2001$ JB001731

Tsai VC, Stewart AL and Thompson AF (2015) Marine ice-sheet profiles and stability under Coulomb basal conditions. Journal of Glaciology 61(226), 205-215. doi: 10.3189/2015JoG14J221

Van Pelt WJ and Oerlemans J (2012) Numerical simulations of cyclic behaviour in the Parallel Ice Sheet Model (PISM. Journal of Glaciology 58(208), 347-360. doi: 10.3189/2012JoG11J217

Winsborrow MCM, Clark CD and Stokes CR (2010) What controls the location of ice streams? Earth-Science Reviews 103(1-2), 45-59. doi: 10.1016/j. earscirev.2010.07.003 